\title{
Improving patient-provider communication about chronic pain: development and feasibility testing of a shared decision- making tool
}

Nananda $\mathrm{Col}^{1^{*}}$ (1) Stephen Hull ${ }^{2}$, Vicky Springmann ${ }^{1}$, Long Ngo ${ }^{3}$, Ernie Merritt ${ }^{4}$, Susan Gold ${ }^{5}$, Michael Sprintz ${ }^{6}$, Noel Genova ${ }^{2}$, Noah Nesin, Brenda Tierman', Frank Sanfilippo², Richard Entel ${ }^{8}$ and Lori Pbert ${ }^{9}$

\begin{abstract}
Background: Chronic pain has emerged as a disease in itself, affecting a growing number of people. Effective patientprovider communication is central to good pain management because pain can only be understood from the patient's perspective. We aimed to develop a user-centered tool to improve patient-provider communication about chronic pain and assess its feasibility in real-world settings in preparation for further evaluation and distribution.

Methods: To identify and prioritize patient treatment goals for chronic pain, strategies to improve patient-provider communication about chronic pain, and facilitate implementation of the tool, we conducted nominal group technique meetings and card sorting with patients with chronic pain and experienced providers $(n=12)$. These findings informed the design of the PainAPP tool. Usability and beta-testing with patients $(n=38)$ and their providers refined the tool and assessed its feasibility, acceptability, and preliminary impact.

Results: Formative work revealed that patients felt neither respected nor trusted by their providers and focused on transforming providers' negative attitudes towards them, whereas providers focused on gathering patient information. PainAPP incorporated areas prioritized by patients and providers: assessing patient treatment goals and preferences, functional abilities and pain, and providing patients tailored education and an overall summary that patients can share with providers.

Beta-testing involved 38 patients and their providers. Half of PainAPP users shared their summaries with their providers. Patients rated PainAPP highly in all areas. All users would recommend it to others with chronic pain; nearly all trusted the information and said it helped them think about my treatment goals (94\%), understand my chronic pain (82\%), make the most of my next doctor's visit (82\%), and not want to use opioids (73\%). Beta-testing revealed challenges delivering the tool and summary report to patients and providers in a timely manner and obtaining provider feedback.
\end{abstract}

Conclusions: PainAPP appears feasible for use, but further adaptation and testing is needed to assess its impact on patients and providers.

\footnotetext{
* Correspondence: Nananda@sdmresourcesinfo

${ }^{1}$ University of New England and Shared Decision Making Resources, 1119 Five Islands Road, Georgetown, ME 04548, USA

Full list of author information is available at the end of the article
}

(c) The Author(s). 2020 Open Access This article is licensed under a Creative Commons Attribution 4.0 International License, which permits use, sharing, adaptation, distribution and reproduction in any medium or format, as long as you give appropriate credit to the original author(s) and the source, provide a link to the Creative Commons licence, and indicate if changes were made. The images or other third party material in this article are included in the article's Creative Commons licence, unless indicated otherwise in a credit line to the material. If material is not included in the article's Creative Commons licence and your intended use is not permitted by statutory regulation or exceeds the permitted use, you will need to obtain permission directly from the copyright holder. To view a copy of this licence, visit http://creativecommons.org/licenses/by/4.0/. The Creative Commons Public Domain Dedication waiver (http://creativecommons.org/publicdomain/zero/1.0/) applies to the data made available in this article, unless otherwise stated in a credit line to the data. 
(Continued from previous page)

Trial registration: This study was approved by the University of New England Independent Review Board for the Protection of Human Subjects in Research (012616-019) and was registered with ClinicalTrials.gov (protocol ID: NCT03425266) prior to enrollment. The trial was prospectively registered and was approved on February 7, 2018.

\section{Background}

Chronic pain is one of the most common reasons adults seek medical care [1]. Opioids became the mainstay of chronic pain treatment in recent decades. When properly used, opioid therapy can improve patients' quality of life, decrease healthcare costs, and improve work productivity. However, misuse and abuse of prescription opioids has reached epidemic proportions (http://www.fda. gov/Drugs/DrugSafety/InformationbyDrugClass/ucm33 0614.htm). The number of drug overdose deaths increased 4-fold between 1999 and 2018 [2, 3], with opioid-related deaths accounting for two-thirds of all drug overdose deaths in 2016 and 2017 [4, 5]. Factors that drove the overuse of opioids were misinformation about its benefits and harms [6], inadequate training of health care providers in pain management, too little clinic time spent with complex patients, and too few multidisciplinary treatment programs $[7,8]$. Yet pain remains undertreated among those most in need. Today's prescription drug crisis reflects a broad failure in managing pain.

Lacking objective measures of pain, healthcare providers must trust their patients' words to understand their pain, its impact on their lives, and their response to treatments. But pain and its treatments can interfere with patients' ability to communicate [9]. Because pain can be exaggerated for secondary gain (for example, liability tort claims) or to obtain opioids that can be misused [10,11], suspicion may be cast on patients with chronic pain [12]. Differences between patients' and providers' attributions about causes of pain further erode the trust that is essential to good communication. Patients who believe their pain is biologic may feel misunderstood when psychological treatments are recommended, or frustrated when no diagnosis is identified [13]. Mandated restrictions to treatments (such as dosing limits) may be blamed on providers, reinforcing feelings of distrust [14]. It is not surprising that many patients with chronic pain feel stigmatized and misunderstood [15] and report being labeled as hypochondriacs or drug seekers [16], while providers feel frustrated and overwhelmed $[17,18]$.

Helping patients communicate their experiences and beliefs about their pain, expectations about treatments, and treatment goals should help providers understand their patients better, which in turn should improve the effectiveness of pain management. The quality of patient-provider communication predicts patient satisfaction better than decreases in reported pain [19-22].
Understanding a patient's goals, values, and expectations is essential because these elements serve as filters through which patients screen their options [23], interpret evidence [24], select treatment [25, 26], and respond to treatment [27]. Patients' and providers' treatment goals [28] and preferences often diverge [29, 30], reinforcing the need for providers to communicate with patients about their goals.

Providers can encourage or impede patient involvement [31]. Providers who engage in partnership-building and supportive talk create opportunities for patients to discuss their needs and be involved [32]. Yet providers only occasionally use partnering or supportive communication, inform patients when there is a decision to be made, present all treatment options, or encourage patients to consider their preferences and goals to guide treatment decisions $[33,34]$. Patients who ask questions and express their concerns and preferences elicit more information and support from their provider [35-37], but many patients are reluctant to engage in collaborative discussions with providers for fear of being seen as a "difficult patient" [38]. Simply asking patients for their preferences is unlikely to yield meaningful responses because patients often have difficulty applying their values to health decisions [33, 34]. Because most providers are not taught how to engage patients in decisions about their health, clinical tools are needed to help with these tasks.

Shared decision-making (SDM) tools, such as decision aids, have been shown in clinical trials to help patients be more informed, experience less decisional conflict, be more involved in decisions about their health, and be more likely to choose treatments that are consistent with their informed preferences and values [39]. However, decision aids for chronic musculoskeletal pain appear far less effective than those developed for other conditions, improving only patients' knowledge about treatment options [40]. A recent systematic review identified 17 randomized controlled trials of decision aids for chronic musculoskeletal pain, all targeting specific pain etiologies (such as hip or knee osteoarthritis). Only four decision aids addressed conservative management strategies [4144]. Most [12] focused on decisions to undergo surgery. These tools have limited relevance to people with chronic pain for whom surgical intervention may no longer be a viable option and whose pain is often multifactorial in etiology, requiring multimodal treatment approaches. 
Utilization of decision support tools in general has been disappointingly low, perhaps because they are typically designed with limited input from patients, little attention to factors that drive utilization, and are uninformed by theory [45]. Patient input, when elicited, is typically achieved through focus groups, but extracting patient priorities from these discussions is subjective and influenced by the investigator's perspectives [46]. In contrast to traditional focus groups, the nominal group technique (NGT) coupled with card sorting, referred to as cognitive mapping, minimizes investigator bias, captures the language of each participant, maintains the autonomy of individual viewpoints, allows equal input by each participant, and objectively prioritizes and organizes findings [47-49]. User-centered design has been proposed as a way to make PDAs more suitable for clinical implementation [50].

To improve utilization, we worked directly with patients and providers, employing user-centered design methods that minimize investigator bias to design the tool.

International standards for developing decision aids [51] recommend that the development process follow a systematic process that involves consultation with patients and clinicians. The process should include scoping and design, developing a prototype, iterative 'alpha' testing with patients and clinicians, and 'beta' testing in 'real life' conditions before producing a final version for use and/or further evaluation. However, only about half of the published reports on decision aids included in the Cochrane review of treatment and screening decision aids [52] were field tested with patients and even fewer had been reviewed or tested by clinicians not involved in the development process. Additionally, few described how they reviewed and synthesized clinical evidence or a distribution strategy.

In order to improve the management of chronic pain, we aimed to develop a user-centered tool that improves patient-provider communication about chronic pain. This manuscript describes findings from cognitive mapping, the development of the tool, and patient and provider responses to the tool.

\section{Methods}

Beta-testing study: participants and recruitment strategy We limited participants to English-speaking adults with access to the Internet who had a diagnosis of a chronic musculoskeletal or neurologic pain disorder resulting in persistent pain lasting over 6 months. We excluded patients whose pain was primarily gastrointestinal, genitourinary, or cardiac in origin because these patients represent a separate medical entity that requires treatment of the underlying cause. We limited beta-testing participants to those with an upcoming appointment to manage their chronic pain within 8 weeks. We included providers who were doctors of medicine (MD), doctors of osteopathic medicine (DO), physician assistants (PA), nurse practitioners (NP), and social workers (MSW) providing they had 2 or more years of clinical experience managing 10 or more patients per month with chronic pain. To ensure that only subjects with a diagnosis of chronic pain were included, participants could only be referred by patient advisers or participating providers who had access to chronic pain patients or patient networks. We purposefully selected diverse patients from different regions of the country. Patient referral networks, including the American Chronic Pain Association), the Southern Maine Chronic Pain Support Group, and a network of multiple sclerosis patients with chronic pain [53] distributed email invitations to their members. We limited beta-testing referrals to a convenience sample of providers who manage patients with chronic pain in Maine and Texas, including pain management centers, primary care settings, and addiction and mental health clinics. We sent participating providers referral cards and emails to distribute to potentially eligible patients. Beta-testing recruitment occurred between November 15, 2017, and June 4, 2018.

Formative research using cognitive mapping informed the design of the PainAPP tool. We conducted structured focus groups using the NGT to identify i) patient treatment goals and preferences, ii) strategies to improve the clinical dialogue surrounding chronic pain, and iii) implementation strategies for distributing the tool, using previously validated methods $[53,54]$.

NGT groups of 5-9 patients or providers responded to one of the following questions: What are the things you want to accomplish in treating your pain? (only patients); What would make it easier to communicate with your doctor [patients] about chronic pain and how to manage it? (patients and providers); and What are the top features that we need to design into the tool to make it both practical and helpful to you in managing your patients with chronic pain? (only providers).

NGT participants silently wrote down their responses, which were later shared, consolidated, and ranked by participants. We later conducted card sorting among a larger sample to organize treatment goals into meaningful clusters. We used hierarchical cluster analysis and multidimensional scaling [55-58] to construct a visual representation (cognitive map) of the data and identify conceptual domains based on how frequently items were sorted into the same category. Figure 1 outlines these methods. All analyses were performed using SPSS Statistics 23 .

The content in PainAPP was guided by findings from this formative work, relevant theory (Table 1) [59, 60], and SDM guidelines [61]. PainAPP includes the key elements identified by patients and providers during cognitive mapping: assessing patient treatment goals and 
preferences, functional abilities, and pain; providing tailored education; and generating a summary that patients can share with their providers. To elucidate topics identified by patients and providers, we created short unscripted videos of people discussing their actual experiences with chronic pain. We also created a short motion graphics video to introduce the tool and explain its use and navigation [62]. All patient-facing content was co-written and iteratively revised by people with chronic pain and reviewed by experienced providers for scientific accuracy. Usability and beta-testing among patients further guided the content and design of PainAPP, resulting in substantial shortening and redesign, including splitting the tool into 2 linked parts.

\section{Beta-testing protocol}

We emailed a link to the study website to patients who responded to the study invitation. The link directed them though the eligibility screener, informed consent document, and baseline questions. Patients were then randomized to either PainAPP or the control group (using Qualtrics' randomization feature). Baseline questions were tailored to the assigned study group to avoid duplication of items that would be subsequently asked in

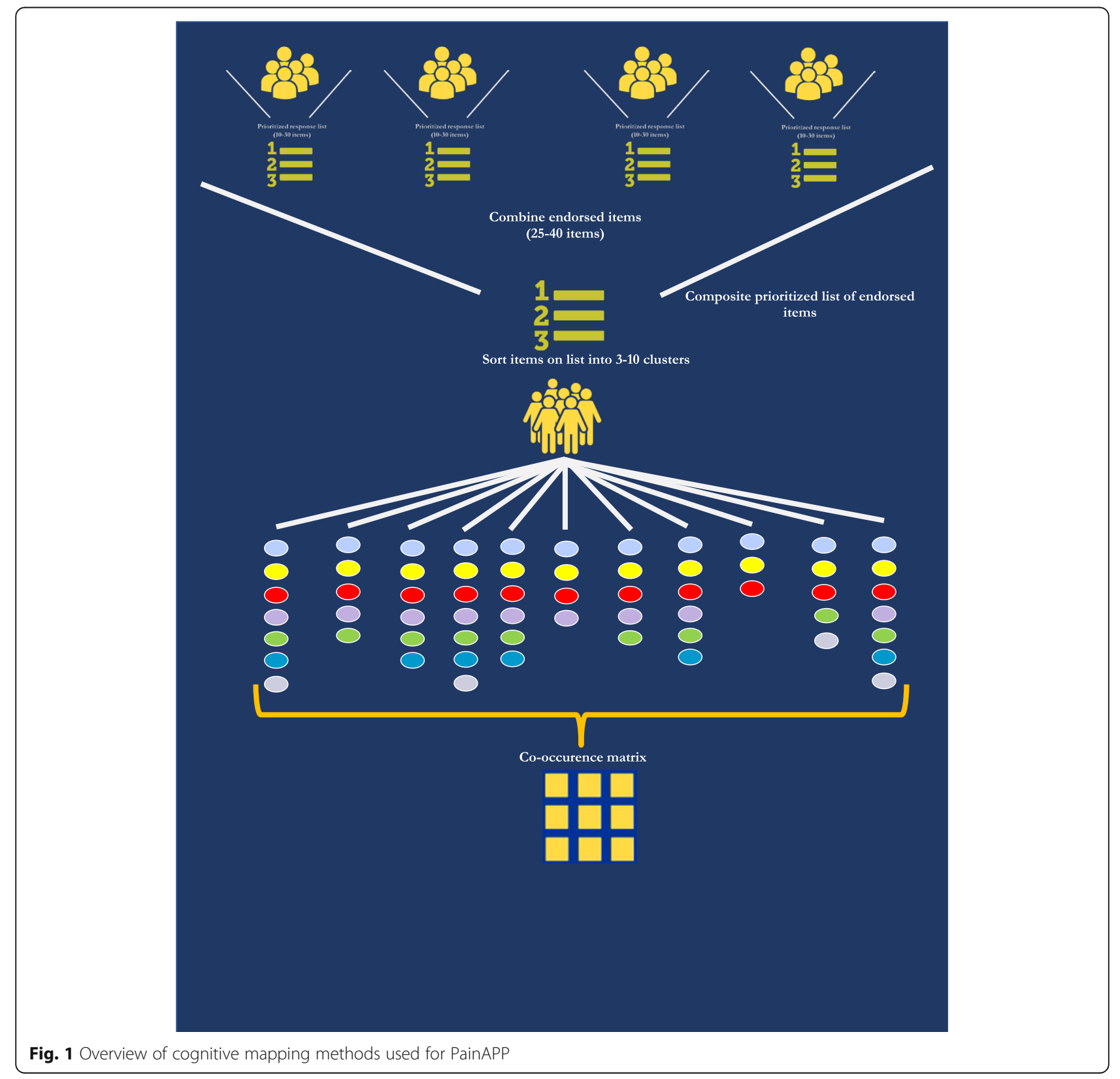


Table 1 Theory-based features of PainAPP

\begin{tabular}{|c|c|}
\hline $\begin{array}{l}\text { Theory-based } \\
\text { recommendation }{ }^{\text {Error! Bookmark }} \\
\text { not defined. }\end{array}$ & Feature in tool \\
\hline Optimize representation & $\begin{array}{l}\text { All preference items and content } \\
\text { were derived from and organized by } \\
\text { experienced patients }\end{array}$ \\
\hline $\begin{array}{l}\text { Include all potentially } \\
\text { appropriate options and their } \\
\text { attributes }\end{array}$ & $\begin{array}{l}\text { All relevant attributes of all options } \\
\text { are shown to patients }\end{array}$ \\
\hline $\begin{array}{l}\text { Suspend selection of an initially } \\
\text { favored option (pre-selection) }\end{array}$ & $\begin{array}{l}\text { Start by focusing only on attributes, } \\
\text { not options. Introduce options } \\
\text { afterwards }\end{array}$ \\
\hline $\begin{array}{l}\text { Remind decision maker of the } \\
\text { array of values }\end{array}$ & $\begin{array}{l}\text { Includes activities that require } \\
\text { attention to the complete array of } \\
\text { values (broad and narrow): choosing, } \\
\text { ranking, rating }\end{array}$ \\
\hline Facilitate weighting of attributes & $\begin{array}{l}\text { Force selection of top 3, then } \\
\text { ranking, then rating of each } \\
\text { subcomponent. }\end{array}$ \\
\hline
\end{tabular}

PainAPP. Subjects randomized to PainAPP were emailed a unique, nontransferable link to the PainAPP tool; control subjects were directed to the control website (https://www. theacpa.org/pain-management-tools/communication-tools/). The control website was chosen based on recommendations of advisers and published quality ratings [63]. Both study groups were emailed identical evaluations immediately after viewing the assigned intervention, after their scheduled provider appointment, and 3-4 weeks later. Patient participants received an incentive payment (\$25 online gift card) after completing the first evaluation and a \$5 gift card for each subsequent evaluation; providers received a single $\$ 50$ gift card.

\section{Beta-testing evaluation and measures}

We used a randomized controlled prospective study design, using an initial 4:1 assignment to PainAPP versus control to be able to assess uptake and utilization of PainApp so that any necessary changes could be addressed. Evaluations obtained after viewing the assigned intervention included: "I would recommend it to others with chronic pain," "I trusted the information provided," "It helped me think about my treatment goals," "It presented unbiased information," "It addressed topics that are important in communicating with my doctor," "It helped me manage my chronic pain," "It will help me make the most of my doctor's visit," "It helped me think about the pros and cons of opioids," "It changed the way I think about opioids," and "It made me not want to use opioid pain medications." Survey responses used a 5-point Likert scale ("strongly agree, somewhat agree, neither agree nor disagree, somewhat disagree, strongly disagree”). Participants were also asked for their suggestions for improving PainAPP.
The following measures were assessed after the subjects' scheduled provider appointment:

Interest in sharing their summary report with their provider. Subjects were asked: "If you received a personal summary report, did you try to share your personal summary report with this provider?" Responses were "yes," "no," "not sure," and "not applicable-I did not receive a personal summary."

Patient-provider communication. Items from the Consumer Assessment of Healthcare Providers and Systems (CAHPS) Adult, Clinician \& Group Survey [64] that were related to SDM were summed to create a composite measure.

Satisfaction with communication was assessed by using the 10-item subscale of the.

The Combined Outcome Measure for Risk Communication and Treatment Decision Making Effectiveness (COMRADE) [65]. Scores are summed to produce a total score (0-20). A higher score corresponds to higher satisfaction.

Pain Intensity was assessed using The Brief Pain Inventory, which rates the severity of pain at its worst, least, average, and currently, and the degree to which it interferes with daily activities (walking, work, mood, enjoyment of life, relations with others, and sleep).

The Control Preference Scale assesses "the degree of control an individual wants to assume when decisions are being made about medical treatment," with roles including the patient making treatment decisions alone, jointly with the physician, or the provider making decisions. Collaborative roles are generally considered preferable to having the provider or patient make decisions alone.

Attitudes towards opioids: For people currently using an opioid, we adapted a survey item related to intention to stop using or reduce opioids from the Prescribed Opioids Difficulty Scale [66]. For those not currently using an opioid, we used the questions: "It made me not want to use an opioid," "It helped me think about the pros and cons of opioids," and "It changed the way I think about opioids."

\section{Beta-testing data analysis}

All data were directly entered by the patient into a Qualtrics database. Use of PainAPP pages was monitored via analysis of website log files. Mean time spent on different activities was computed after removing outliers that likely reflected break periods. We could not directly determine how much time participants spent on the control website because we did not have access to that website's log file. Because of the small sample size, the limited scope of the beta-testing, and biases detected during beta-testing, limited statistical analyses were performed. Recruitment was ended before our initial target of 50 patients was achieved because of serious challenges 
discovered that prompted a reassessment of the study design. The initial target sample of 50 was estimated to provide an $80 \%$ chance of detecting a $20 \%$ improvement on the primary outcome COMRADE with a type-I error rate of 0.05 [67].

\section{The intervention}

PainAPP is an interactive, online decision support tool that employs a tunnel design [68] to guide users through a series of structured, interactive modules (Fig. 2). Multi-tiered values clarification exercises help users identify and prioritize their treatment goals and preferences by asking them to select and rank the most important broad goals from a list of nine domains (for example, "managing pain," "having a better quality of life," and "reducing fear, anger, and depression"). Next, users are asked to rate the importance of more detailed goals that are conceptually related to the goals that were selected, using a 4-point Likert scale ("not important or does not apply," "somewhat important," "important," and "very important"). All pre-programmed treatment goals were generated by patients with chronic pain during cognitive mapping. Additional goals can be added by the user. A summary of the patient's goals and preferences is generated along with guidance on using these goals to manage pain (Fig. 3).
PainAPP consists of 2 linked parts that can be used independently or sequentially. Part 1 focuses on patient engagement, clarifying patient goals and preferences and providing tailored education. Part 2 includes a comprehensive pain assessment (including risk for opioid misuse, psychosocial comorbidities, and lifestyle risk factors) coupled with educational feedback tailored to the patient's reported risks and preferences. Information entered in Part 1 is recalled in Part 2. Both parts generate a succinct structured summary, shown during use and emailed to the patient upon completion (Fig. 4). The patient can share the summary with his or her provider by either copying it into the patient portal, emailing it, printing it, or through a mobile device.

The tool emphasizes patient engagement, provider partnership, and communication. Features include: accessibility on multiple platforms, scalability, encryption, HIPAA compliance, and various options for dissemination. Content employs principles of effective communication [34] such as positive framing, side-byside comparisons, graphics, encouragements and commendations upon completing sections, plain language, highlighting of important information, and a user-driven path. The tool was created using customized Qualtrics $\odot$ software (Seattle, WA). The study adheres to CONSORT guidelines.

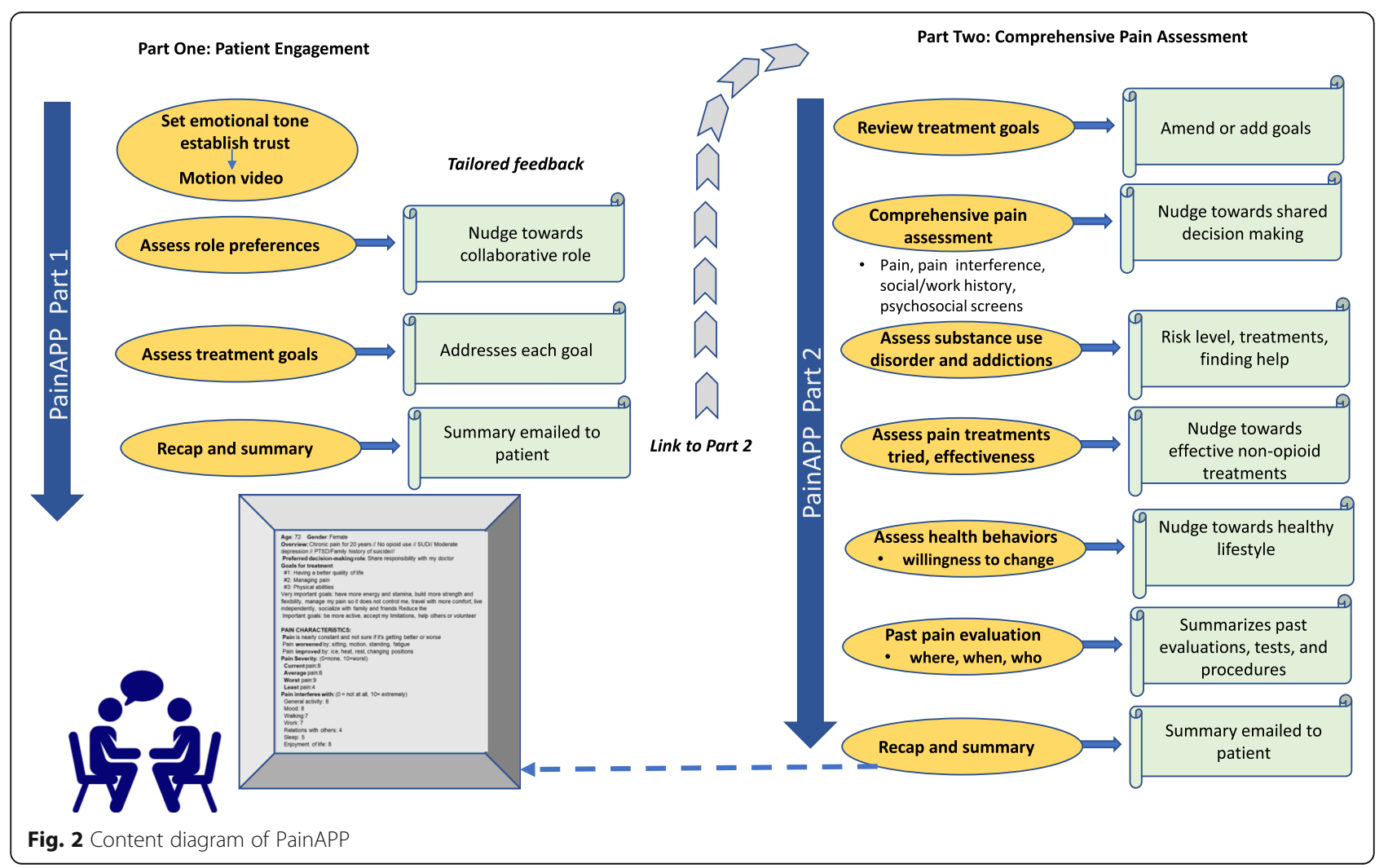




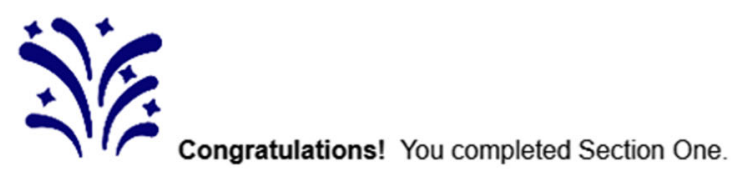

Setting realistic goals for yourself that go beyond pain relief is the most important step on your path to better health.

- It can be difficult to accept that the pain itself may never completely go away. You may always have some pain or discomfort. Finding better ways to live your life with your pain and focusing on the things you can do will help you achieve your goals. This does not mean giving up on efforts to lessen your pain.

- Most patients find that the more they focus on the good things in their life, the easier it is to cope with their pain.

Your goals will likely change over time as your health changes and your life changes. Keep your goals in mind as you make the changes necessary to manage your pain.

Here are your treatment goals and preferences:

Preferred decision-making role: Share responsibility with my doctor when deciding what treatment is best for me

\section{Goals for treatment}

\#1: Thinking, memory, and concentration

\#2: Having a better quality of life

\#3: Your healthcare providers

Very important goals: live independently, do more chores, maintain or improve memory, have providers

who listen to me and understand my pain and limitations

Fig. 3 Sample summary of patient treatment goals and preference

\section{Results}

Part 1. Cognitive mapping

Treatment goals

Sixteen patient subjects consented (50\% female, $87 \%$ white, mean age 57 years) and completed the NGT activities. Two NGTs involving 8 patients each, conducted in February and April 2016, yielded 37 unique patientidentified treatment goals. Sixteen patient subjects consented to the card sorting exercise and completed all ratings; 15 completed the card sorting (94\%). The 2dimensional solution for the multidimensional scaling analyses indicated robust goodness-of-fit measures (stress $=.1041)$. The most endorsed goal for patients (100\%) was "To have providers who understand my pain and limitations" (Table 2). Ten patient clusters were derived from the 37 patient treatment goals. The most important cluster was Physical activity and stamina, followed by You and your providers, and Pain management. The least important was Medication management.

We interpreted one dimension of the patients' cognitive map as ranging from factors internally controlled by the patient to factors externally controlled, the other dimension ranging from emotional/social function to physical/cognitive impact (Fig. 5).

\section{Communication strategies}

Three NGTs involved 14 patient participants (67\% female) and 7 provider participants (MD, DO, and PA). Forty-one unique communication strategies were generated by patients, 35 by providers. The most important patient-generated strategies were: "clinician takes me seriously and respects my input" and "being involved as an integral part of my treatment team." The most important provider-generated strategy was "knowledge of past work-up," followed by "timeline of the pain." Strategies prioritized by both patients and providers were "improved provider teamwork," "more time allotted for consultations," and "better knowledge about the underlying condition." Both groups prioritized knowledge about their condition over knowledge about treatment options (Table 3). 


\section{Sample provider report}

Age: 77 Gender: Female

Overview: Chronic pain for 30 years // No opioid use // no SUD// No depression // /injury to my right shoulder, twice injury to my low back, and tail pain, plus tinnitus, asthma and patulous eustachian tube of both ears, hearing loss//

Preferred decision-making role: Make the final selection myself about

which treatment I will receive.

Goals for treatment

\#1: Managing pain

\#2: Physical abilities

\#3: Thinking, memory, and concentration

Very important goals: have more energy and stamina, build more strength and flexibility, manage my pain so it does not control me, address pain that disrupts my sleep, think more clearly Important goals: be more active, accept my limitations, better understand my condition, tolerate light, odor, or noise better, maintain or improve memory, improve concentration; To continue to take care of my basic daily needs: cooking \& clean up, caring for my dear cat. Concerns to discuss with doctor: The doctors have told me I need to gain weight, but that is hard when I have digestive problems. Believes pain is caused by: nerve damage

How pain started: An injury: in a car or motorcycle,

Pain is constant and getting worse

Pain worsened by: sitting, lying on my back

Pain improved by: ice, heat, walking, exercise (other than walking)

Pain Severity: $(0=$ none, $10=$ worst $)$

Current pain: 4

Average pain: 3 Worst pain: 5 Least pain: 2

Fig. 4 Sample provider summary generated by PainAPP
Pain interferes with: $(0=$ not at all, $10=$ extremely $)$

General activity: 5

Mood: 3

Walking:3

Work: 5

Relations with others: 5

Sleep: 4

Enjoyment of life: 4

Usually needs help with: taking public transportation, household chores

No past opioid use // No current opioid use

Interest in changing treatment? Not sure.

Treatments that helped: Very helpful: Acupuncture, Meditation, Prayer

Somewhat helpful: Talk therapy, Support group, PT, OT, Chiropractic or

osteopathic manipulation, Yoga, Tai chi, or Pilates, Massage

Treatment failures: -- Harmful: None

Willing to try: Group counseling, Occupational therapy

Not willing to try: Injections, Surgery;

Why: Injections: Can't handle it// Surgery: Can't handle it//

Medical History: injury to right shoulder, twice injury to my low back, tinnitus,

asthma and patulous eustachian tube, Bowel problems, Weakness-all over-

especially when I think too much about how I feel. Numbness or tingling-in my lower legs and feet

Psychological History: Not depressed (self-rated based on PHQ-2). Anxiety

disorder likely (self-rated based on PHQ-2).

Childhood abuse: no

Health behaviors: No tobacco use / nondrinker / Exercise: 7 times per week

Perceived weight: Underweight

Medication adherence: patient does not take any prescription medications

Social History: divorced, lives in single-floor house or apartment, retired

Pain evaluation:

Primary care: southern maine medical, biddeford, me, 2018//Specialist:

neurologist, biddeford, me, 2018//

\section{Clinical integration}

We conducted one NGT involving 5 provider participants. Providers felt the tool would be most helpful if it helped them assess functional abilities and pain history (Table 4).

\section{Part 2. Beta-testing findings}

Of the 61 patients who opted in and were emailed invitations to participate, $43(70 \%)$ initiated screening, and of those, 38 (88\%) were eligible and consented (Fig. 6). Completing the intake process took $20.7 \mathrm{~min}$ on average; Patient Engagement and Education (Part 1) took an average of $28.0 \mathrm{~min}$; Comprehensive Pain Assessment (Part 2) took an average of 27.3 min. Patients using the control site reported spending between 15 and $60 \mathrm{~min}$ on the site (average $28 \mathrm{~min}$ ). Just over half of patients (56\%) were referred by providers, the remainder (44\%) by patient networks. Socio-demographics of participants are shown in Table 5.

Of the 17 patients who completed both components of PainAPP, half [7] wanted to share their summary report with their provider; 3 (37.5\%) by printing it and bringing it to the clinic visit, $3(37.5 \%)$ requested that it be mailed to them because they do not have a printer, and 2 (25\%) opted to use a patient portal. Among the 16 subjects assigned to PainAPP who completed the post-provider visit, half [7] reported trying to share their summary report with their provider, 2 weren't sure, 2 reported that it was not applicable because they did not receive it, and 4 did not try to share it. Among the 4 who reported not sharing their summary, 1 forgot, 1 reported that there was "no time and [their provider] did not seem that accessible"; one gave a non-informative response ${ }^{1}$; and one offered no explanation. None of the patients in the control group received a personal summary as this was not a feature of that website. Curiously, 3 of these 5 control subjects reported receiving a summary, one of whom reported sharing the summary with his/her provider, one reported not sharing it because it was received at the end of the visit, and one was not sure if he/she shared the summary with the provider.

Half of all subjects (48\%) preferred to make the final treatment selection themselves after seriously considering their doctor's opinion, 13\% preferred to share responsibility with their doctor, and $7 \%$ preferred their doctor make the final decision after considering their opinion; none preferred to leave all decisions to their provider. Six (35\%) of PainAPP users became more engaged with decision making after using the tool, changing their role preferences toward a more collaborative or independent role.

Both PainAPP and the control website achieved high ratings by most subjects on evaluation measures assessed

\footnotetext{
${ }^{1}$ This response was: "We discuss my fibromyalgia pain and changes each appointment briefly"
} 
Table 2 Ratings of prioritized patient treatment goals ("Topics most important to you when you are choosing ways to manage or treat your chronic pain")

\begin{tabular}{|c|c|c|}
\hline \multirow{2}{*}{$\begin{array}{l}\# \\
\text { Physical activity and stamina }\end{array}$} & \multicolumn{2}{|c|}{$\begin{array}{l}\text { Importance Rating } \\
\text { (Mean, SD) }\end{array}$} \\
\hline & 9.71 & 0.48 \\
\hline To be able to do more with less pain & 9.79 & 0.41 \\
\hline To have more energy and stamina and less fatigue & 9.79 & 0.56 \\
\hline To pace myself, set reasonable expectations, listen to my body, and know my limitations & 9.71 & 0.45 \\
\hline To be more physically fit (strength and flexibility) within my limitations & 9.57 & 0.49 \\
\hline You and Your Providers & 9.62 & 0.50 \\
\hline To have providers who understand my pain and limitations & 10.00 & 0.00 \\
\hline To have a team of providers who work together to help me & 9.71 & 0.59 \\
\hline To be able to explain better to my providers how I feel & 9.14 & 0.91 \\
\hline Pain Management & 9.45 & 0.62 \\
\hline To reach a point where pain does not control my day & 9.79 & 0.41 \\
\hline To manage pain at a reasonable level & 9.50 & 0.50 \\
\hline To learn more about chronic pain or my condition and how to deal with it better & 9.29 & 0.80 \\
\hline To learn strategies to help me ease my pain & 9.21 & 0.77 \\
\hline To be able to tolerate things like light, odor, noise & 8.21 & 1.15 \\
\hline To reduce pain at night [allowing me to sleep better] & 9.07 & 1.03 \\
\hline Costs & 9.29 & 0.80 \\
\hline To find a treatment [or medical equipment I can afford] & 9.29 & 0.80 \\
\hline \multicolumn{3}{|l|}{ To find an alternative treatment I can afford } \\
\hline Living a more independent and satisfying life & 9.23 & 0.80 \\
\hline To travel or commute with more comfort & 9.36 & 0.61 \\
\hline To be able to sit comfortably & 9.36 & 0.81 \\
\hline To be able to live independently in my home & 9.21 & 1.01 \\
\hline To be able to do more household chores & 9.00 & 0.76 \\
\hline To help others & 9.57 & 0.49 \\
\hline To lead a fuller life & 9.57 & 0.62 \\
\hline To be able to work & 8.43 & 1.05 \\
\hline Better memory, thinking, and focus & 9.07 & 0.88 \\
\hline To improve or maintain clear thinking & 9.07 & 0.88 \\
\hline \multicolumn{3}{|l|}{ To retain and recall information } \\
\hline \multicolumn{3}{|l|}{ To be better able to focus } \\
\hline Managing depression and emotions & 8.91 & 0.91 \\
\hline To be less irritable and able to deal better with stress & 9.29 & 0.80 \\
\hline To be able to look forward to the future instead of being focused on my pain & 9.21 & 1.01 \\
\hline To develop better ways to deal with depression & 9.00 & 1.00 \\
\hline To be able to control anger and aggressive thoughts & 8.57 & 0.90 \\
\hline To reduce my fear of being in pain & 8.50 & 0.82 \\
\hline Friends, family, and intimacy & 8.88 & 1.08 \\
\hline To maintain relationships with family and friends & 9.07 & 0.96 \\
\hline To be able to socialize and reduce isolation & 8.86 & 0.99 \\
\hline To improve or maintain sexual relations & 8.71 & 1.28 \\
\hline
\end{tabular}


Table 2 Ratings of prioritized patient treatment goals ("Topics most important to you when you are choosing ways to manage or treat your chronic pain") (Continued)

\begin{tabular}{|c|c|c|}
\hline ( & $\begin{array}{l}\text { Impc } \\
\text { (Mea }\end{array}$ & \\
\hline Minimal and natural treatments & 8.77 & 0.76 \\
\hline To avoid side-effects that cause more problems & 9.57 & 0.49 \\
\hline To avoid surgery & 9.29 & 0.80 \\
\hline To be able to handle pain using natural and/or alternative treatments & 9.14 & 0.64 \\
\hline Medication management & 8.52 & 1.12 \\
\hline To minimize or eliminate my pain medications & 8.71 & 1.10 \\
\hline To maintain current level of pain medications & 8.29 & 1.03 \\
\hline To have enough medication to adequately treat my pain & 8.57 & 1.24 \\
\hline To become pain-free regardless of side effects & 7.07 & 1.10 \\
\hline
\end{tabular}

immediately after use (Fig. 7). Because of the small sample size, high attrition rate, and the small number of people in the control group, no meaningful comparisons can be made. Nearly all PainAPP users strongly or somewhat agreed that I would recommend it to others with chronic pain (100\%), It addressed topics that are important in communicating with my doctor (100\%), and I trusted the information (94\%).

Statistical testing of the null hypothesis of no difference between the study and controls group could not be

\section{Treatment Goals; Patients; $\mathbf{n = 1 3}$ Chronic Pain}

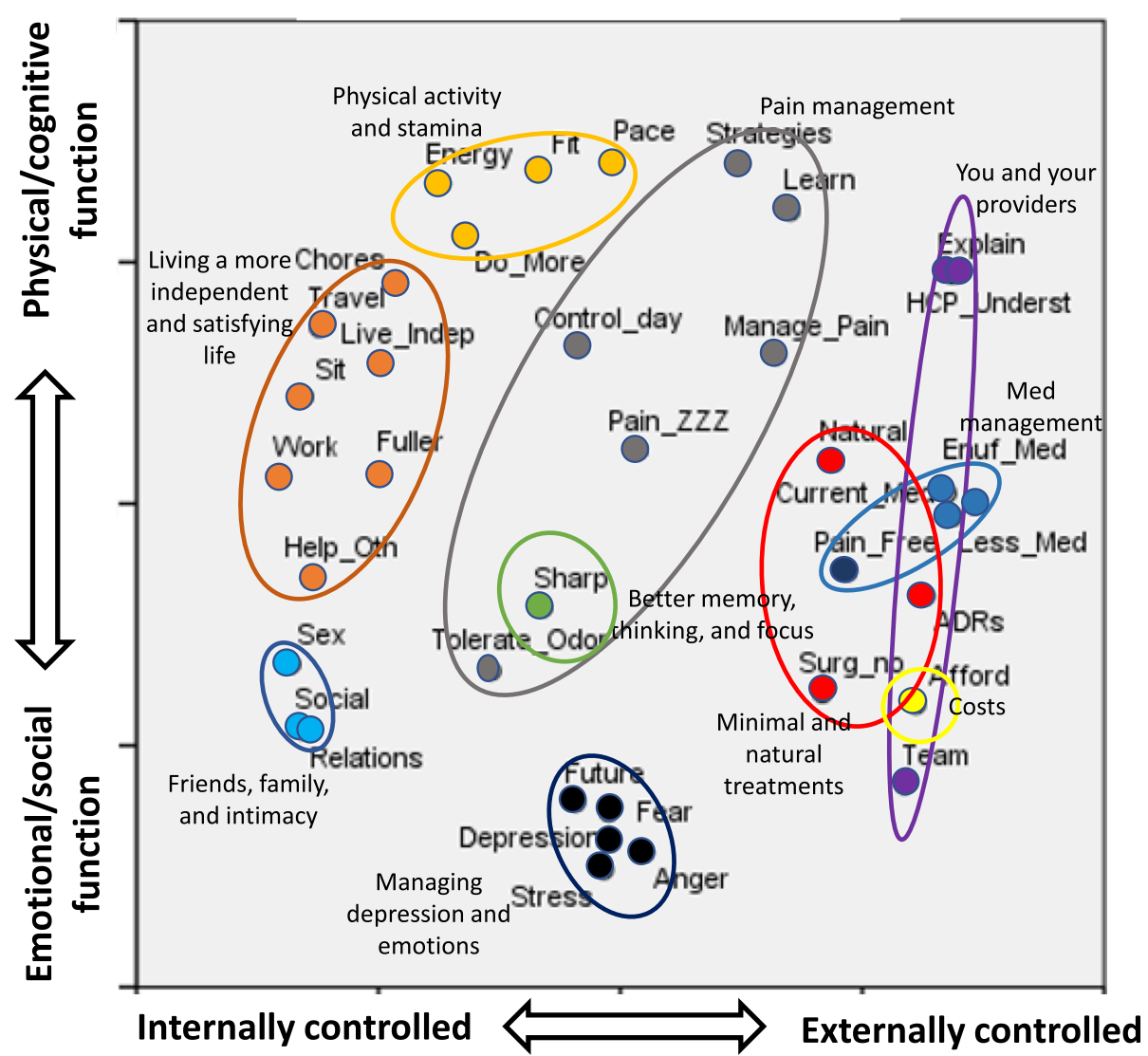

Fig. 5 Cognitive map of patient treatment goals $(n=13)$ 
Table 3 Comparison of patient and provider identified communication strategies to improve chronic pain discussions

\begin{tabular}{ll}
\hline Top 10 patient factors & Top 10 providers factors \\
\hline $\begin{array}{l}\text { The clinician takes me seriously } \\
\text { and respects my input }\end{array}$ & $\begin{array}{l}\text { Past work-up and outcomes of the } \\
\text { presenting problem/ source of } \\
\text { pain }\end{array}$
\end{tabular}

Be told about all options and side- Having a clear timeline of the pain effects

The clinician is knowledgeable about my particular condition

Ask how I want to manage it/ accept that I am in charge of my

health/ I am involved as an integral

part of my treatment team

Take the time needed, not rush

Hear the patient's expectations about their pain

Talk to me not the computer/ make eye contact/ read the medical file before, not during, the appointment

Let me know that he's

communicated with other docs taking care of me

To have an encouraging doctor/ never leave me feeling utterly helpless, hopeless, or written off

Have a trusting relationship with my provider

Hearing how they believe their pain has impacted their daily lives, outlook, \& relationships

Listen to their story, allow them to vent

A clear history of past treatments tried and whether they helped or not

Have enough time with the patient ( $>30$ minutes)

Knowing of any adverse childhood experiences

Better use of behavioral and mental health

No judgment/ not look at me as if Clarify common

I'm faking it/ feel like doctors aren't misunderstandings about pain*

stigmatizing me for my pain or Assess patient's support system* way of life

*signifies that these 2 items were tied for 10th place

done due to small sample size.. Exploratory analyses are shown in Additional file 1: Appendix 1.

We emailed 12 invitations to evaluate the tool to participating providers, which yielded one provider's evaluations of 2 patients. Both evaluations were non-informative because the two patients evaluated had not chosen to share their report with their provider, leading the provider to respond to all questions with "not applicable". The providers of patients referred through patient networks could not be contacted.

No harms or unintended effects were reported.

\section{Discussion}

Our formative work confirmed both the challenges and importance of patient-provider communication in managing chronic pain. The most important single treatment goal articulated by patients addressed communication"having a provider who understand their pain and limitations". The strategies prioritized by patients to improve patient-provider communication reveal that patients with chronic pain felt neither respected nor trusted by their providers, elements that are essential to effective communication. Strategies prioritized by providers
Table 4 Top ranked features to improve clinical integration (providers only)

Rank What are the top features that we need to design into the tool to make it both practical and helpful to you in managing your patients with chronic pain?

$1 \quad$ Assess functional abilities and limitations

2 Provide pain history components (location, duration, history of onset, history of evaluation to date, associated symptoms, aggravating and ameliorating factors, current treatment, tried but failed treatment, etc)

3 Presenting a patient prioritized list of the patient's goals for the encounter

4 Educate the patient on effectiveness of CBT, ACT and the emotional components of pain

5 Scripts to guide difficult conversations regarding changing a longstanding treatment plan

6 Educate the patient that reporting pain will not lead to prescription for pain med.

$7 \quad$ Screening tools for substance use disorder and/or opioid use disorder

8 Resource list customized by community (treating substance use disorder, acupuncturists, osteopaths, chiropractors, massage therapists, Tai Chi, etc.)

9 Require minimal effort by providers (not have to click too many boxes or write a whole lot)

10 Easy to read and follow

11 Facilitate the patient providing a signed release to facilitate obtaining past records in advance of the patient encounter

12 Keep it short

13 Gives multiple choice options which reflect the wide range of patient/provider possible responses

14 Include tools to help with motivational interviewing regarding pain and function

15

Easy access to MME calculator

reveal their struggles with gathering information about their patients. While patients focused on transforming providers' negative attitudes towards patients with chronic pain, providers focused on gathering information about their patients. Providers prioritized collecting biologic over psychosocial data, yet many of the treatment goals identified by patients addressed complex nonbiologic constructs such as preserving independence, pacing oneself, managing emotions, and obtaining affordable treatments. While few of the communication strategies prioritized by patients or providers mapped to key elements of SDM, helping providers with data collection might indirectly promote SDM by freeing up time to discuss the patient's preferences and concerns.

Preliminary testing suggests that PainAPP was wellreceived by patients, appears user-friendly, and the summary page appears potentially useful for patients, whether shared with providers or not. Evaluations obtained just after using the tool were generally favorable though findings after the provider visit were mixed. 


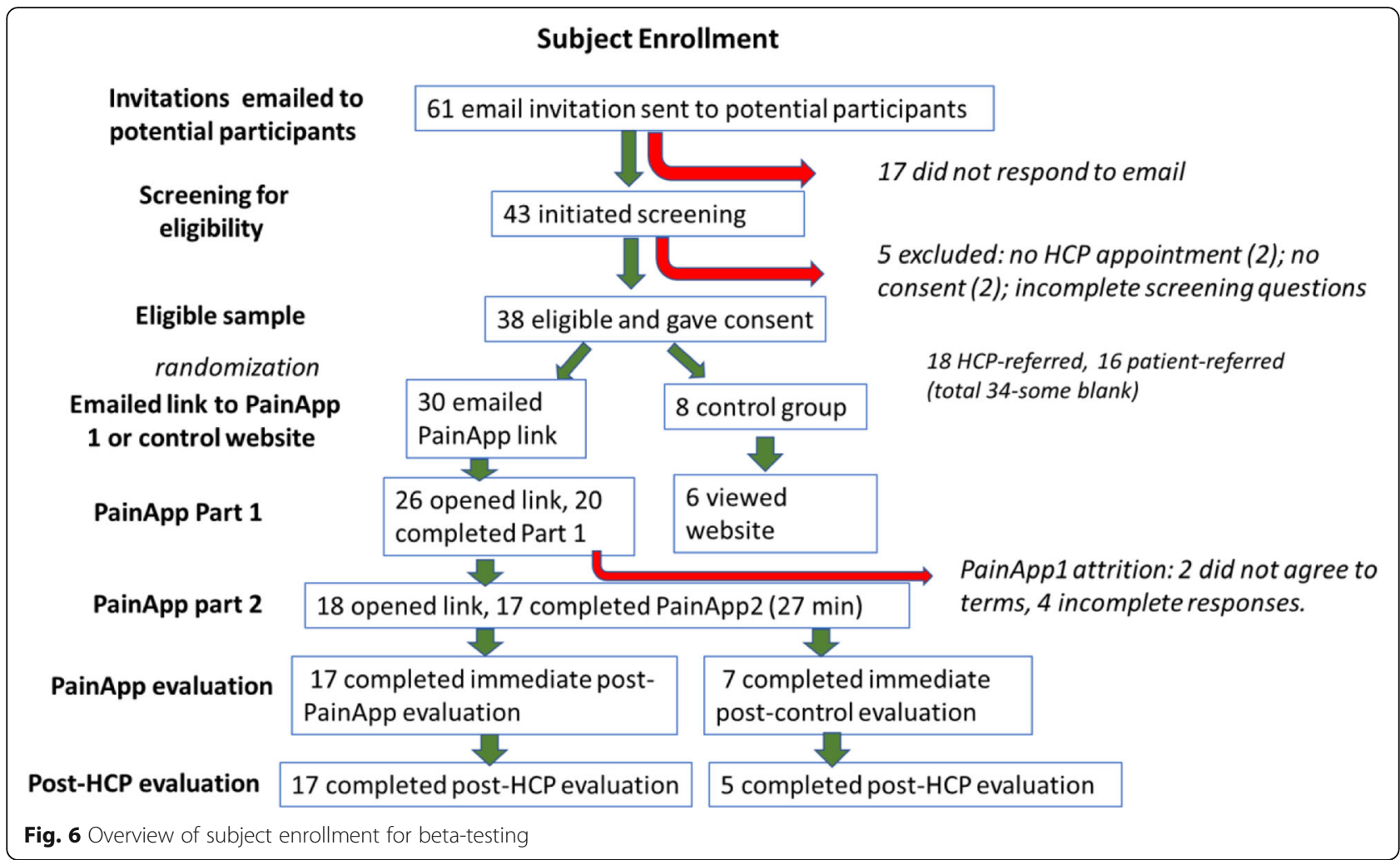

Overall PainAPP appears feasible for use but more rigorous testing is needed.

Our study highlights several challenges with our usercentered design process. Systematically identifying and prioritizing patient and provider goals and communication strategies using cognitive mapping techniques provided valuable insights but was very time consuming. Balancing the priorities of patients with those of providers in the design of the tool was time-consuming and difficult to navigate. Early testers tended to add (rather than remove) sections or features to the tool, resulting in serial lengthening of the tool. Determining the optimal length of the tool was a formidable challenge. After many users found the tool too long, it was redesigned, introduced more skip patterns, emailing content to be read later, and separating it into two parts connected via an emailed link. These changes streamlined the tool but introduced some confusion. Some patients lost the link to Part 2 or did not understand why there was a Part 2.

Tension between comprehensiveness and brevity permeated the development process. Providers requested detailed information about the patient be included in the summary page, yet also wanted the summary to be short and easy to read. Several of the providers who helped guide the development of PainAPP lacked enthusiasm to distribute or use the tool with their patients. This could reflect inadequacies in the summary page content, lack of integration of the tool into clinical workflow, and/ or the heavy workload of providers. The NGT may not have been ideal for identifying implementation strategies for decision support tools because few participating providers had direct experience with these tools. Including providers and practice managers experienced with decision support may have yielded more robust findings.

Beta-testing revealed serious flaws with our study design and the intervention itself that were not previously identified. High attrition rates likely reflected the coupling of a time-intensive study protocol with a timeintensive, two-part online intervention. The opt-in procedures coupled with lengthy consent documents and baseline surveys required nearly as much time as did the intervention itself ( $21 \mathrm{~min}$ versus $30 \mathrm{~min}$, respectively). Most attrition occurred during the intake process, losing 23 (38\%) from our invited sample. Attrition was also high during completion of Part 1 of PainAPP (losing an additional 10 participants) and Part 2 of PainApp (losing an additional 3 participants). Intake surveys and assessment evaluations were intentionally administered separated from the intervention to minimize patient burden and help subjects better understand the boundaries of the intervention, but the use of multiple sequential surveys created confusion, as several patients mistook the baseline questionnaire for the intervention itself. 
Table 5 Baseline patient participant demographic and clinical characteristics (beta-study) $(n=38)$

\begin{tabular}{|c|c|c|c|}
\hline Characteristic & Combined $(n=38)$ & PainAPP $(n=30)$ & Control $(n=8)$ \\
\hline Mean age, years (range) & $56.5(22-80)$ & $56.9(22-75)$ & $55(41-80)$ \\
\hline \multicolumn{4}{|l|}{ Gender, n (\%) } \\
\hline Male & $12(31.6)$ & $9(30.0)$ & $3(37.5)$ \\
\hline Female & $26(68.4)$ & $21(70.0)$ & $5(62.5)$ \\
\hline \multicolumn{4}{|l|}{ Race, n (\%) } \\
\hline White/Caucasian & $32(84.2)$ & $25(83.3)$ & $7(87.5)$ \\
\hline Black or African American & $2(5.3)$ & $2(6.7)$ & 0 \\
\hline Latino or Hispanic & $2(5.3)$ & $1(3.3)$ & $1(12.5)$ \\
\hline Native American or Alaska Native & $2(5.3)$ & $2(6.7)$ & 0 \\
\hline Other & 0 & 0 & 0 \\
\hline \multicolumn{4}{|l|}{ Education, $\mathrm{n}(\%)$} \\
\hline High school graduate or GED & $6(15.8)$ & $5(16.7)$ & $1(12.5)$ \\
\hline Some college or 2-year college or technical school & $10(26.3)$ & $7(23.3)$ & $3(37.5)$ \\
\hline 4-year college graduate & $10(26.3)$ & $7(23.3)$ & $3(37.5)$ \\
\hline More than 4-year college degree & $12(31.6)$ & $11(36.7)$ & $1(12.5)$ \\
\hline \multicolumn{4}{|l|}{ Primary cause of chronic pain (\%) } \\
\hline Back pain & $14(36.8)$ & $13(43.3)$ & $1(12.5)$ \\
\hline Fibromyalgia & $6(15.8)$ & $4(13.3)$ & $2(25.0)$ \\
\hline Neck pain & $4(10.5)$ & $4(13,3)$ & 0 \\
\hline Nerve pain & $4(10.5)$ & $3(10.0)$ & $1(12.5)$ \\
\hline Other musculo-skeletal & $8(21.1)$ & $5(16.7)$ & $3(37.5)$ \\
\hline Complex Regional Pain Syndrome & $1(2.6)$ & 0 & $1(12.5)$ \\
\hline Other & $1(2.6)$ & $1(3.3)$ & 0 \\
\hline Years with chronic pain, Mean (SD; range) & $17.53(12.13 ; 2-50)$ & $17.45(13.0 ; 2-50)$ & $16.13(8.2 ; 8-30$ \\
\hline Past alcohol or drug problem, $\mathrm{n}(\%)$ & $6(15.8)$ & $5(16.7)$ & $1(12.5)$ \\
\hline Current daily tobacco use & $8(21.1)$ & $7(23.3)$ & $1(12.5)$ \\
\hline \multicolumn{4}{|l|}{ Use of opioid medications, $n(\%)$} \\
\hline Yes, currently & $17(44.7)$ & $13(43.3)$ & $4(50.0)$ \\
\hline Yes, in past but not now & $12(31.6)$ & $10(33.3)$ & $2(25.0)$ \\
\hline No & $9(23.7)$ & $7(23.3)$ & $2(25.0)$ \\
\hline \multicolumn{4}{|l|}{ Overall health (self-reported) } \\
\hline Excellent & 0 & 0 & 0 \\
\hline Very good & $11(9.0)$ & $9(30.0)$ & $2(25.0)$ \\
\hline Good & $15(39.5)$ & $12(40.0)$ & $3(37.5)$ \\
\hline Fair & $12(31.6)$ & $9(30.0)$ & $3(37.5)$ \\
\hline Poor & 0 & 0 & 0 \\
\hline \multicolumn{4}{|l|}{ Overall mental or emotional health (self-reported) } \\
\hline Excellent & $4(10.5)$ & $4(13.3)$ & 0 \\
\hline Very good & $9(23.7)$ & $6(20.0)$ & $3(37.5)$ \\
\hline Good & $13(34.2)$ & $13(43.3)$ & 0 \\
\hline Fair & $8(21.1)$ & $5(16.7)$ & $3(37.5)$ \\
\hline Poor & $4(10.5)$ & $2(6.7)$ & $2(25.0)$ \\
\hline
\end{tabular}




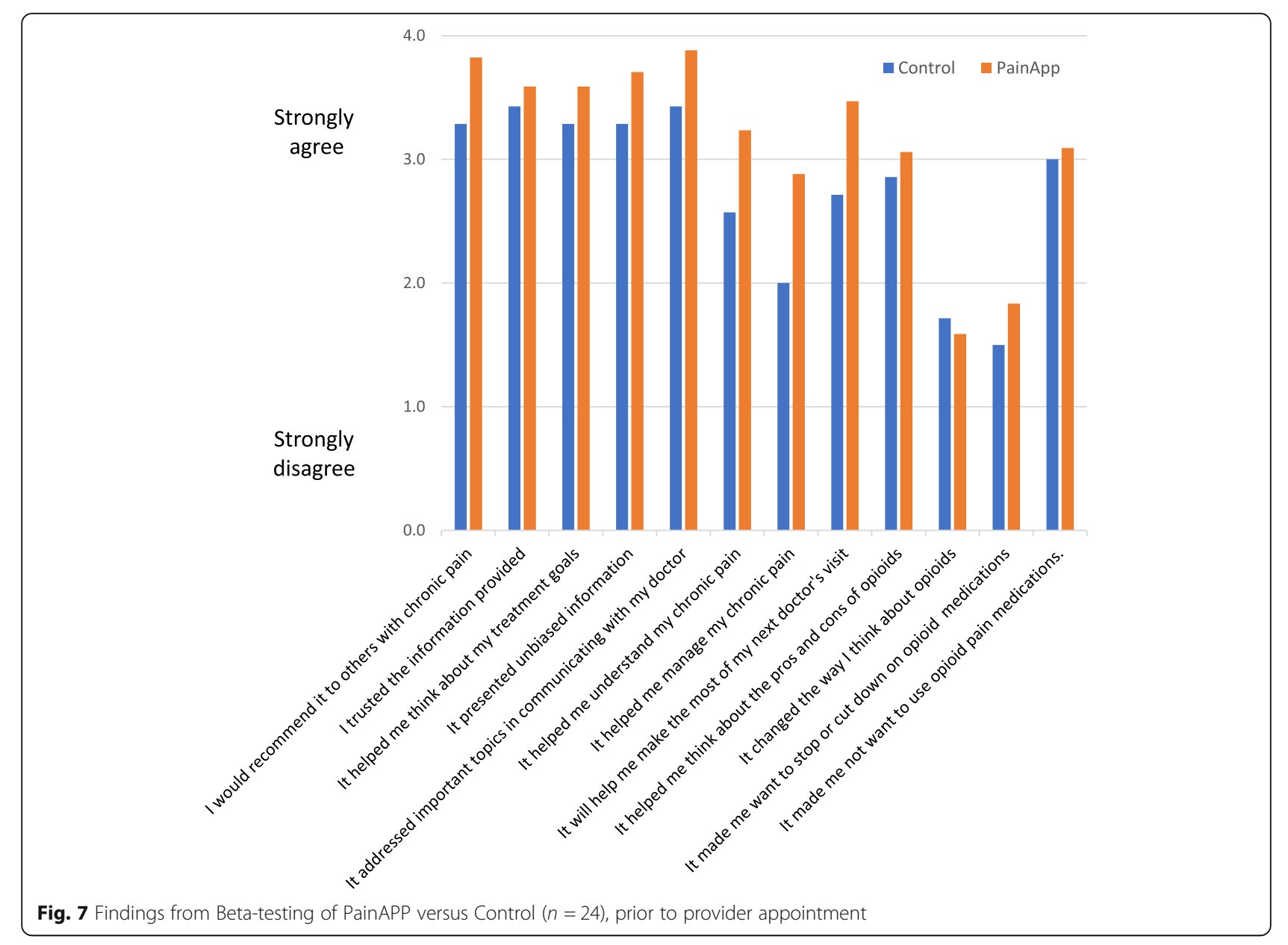

Splitting up the intervention into 2 parts compounded this problem. Our choice of control website further compromised our analyses. Whether and how participants used the control site website could not be monitored. Further, many participants were referred to the study through the sponsor of the control website, which may have motivated those subjects to give overly positive evaluations of the control website if randomized to the control group. The functionalities of the two interventions differed substantially--only PainAPP generated a sharable summary and assessed goals--making comparisons of features only included in one website less meaningful. Comparing PainAPP to standard of care might have avoided these difficulties. To minimize patient burden, questions that were asked in PainAPP (but not the control) were not duplicated in the baseline survey for those assigned to PainAPP. However, this compromised our pre-post evaluation of PainAPP because these items were effectively asked after completing parts of the intervention, thus not capturing pre-intervention status. PainAPP may have altered participants' perspective and attitudes when answering questions, given that we observed a shift in preferences for decision-making after viewing the intervention. A retrospective pre-post design may have been more appropriate for this intervention. Such a design is more sensitive and valid [69] than a randomized controlled trial if the intervention prompts a change in the frame of reference that participants use to assess their attitudes, underestimating the intervention's effects [70-74].

Embedding PainAPP into the electronic health record (EHR) should facilitate its integration into clinical workflow and minimize many of the difficulties encountered. Dissemination could be triggered when scheduling appointments, and the summary page could be automatically embedded into the patient's record, facilitating sharing at point-of-care. With additional resources, PainAPP could potentially be embedded into EHRs, either in its entirely or in modules. It could also be customized to different clinical practices or settings and linked to quality improvement metrics. PainAPP could also be reprogrammed as a mobile App. However, reprogramming an interactive tool as complex as PainAPP into either an EHR or mobile App would be a daunting and error- 
prone undertaking. To integrate PainAPP into clinical workflow without the benefit of being integrated into an EHR, PainAPP (or an abbreviated version of PainApp) should be distributed to patients 1-2 weeks before their appointments and delivery of their summary report to their provider should be automated. The PainAPP summary could replace the cumbersome paper-based medical history form that is often used in waiting rooms.

Our beta-testing provided insights to guide future evaluation and distribution. Referrals from both providers and patient-networks appear feasible and capture different population segments. Referrals from pain specialists exclude those lacking access to specialty care; referrals from patient networks exclude socially isolated patients. Combined approaches for dissemination, using both provider and patient networks, may be the optimum strategy for broad distribution.

Our study has many limitations. Our sample size for NGTs and cognitive mapping was small. However, we were able to achieve model convergence with nonparametric multidimensional scaling and hierarchical cluster analysis. Two references support the use of these methods where the power analysis was carried out via Monte Carlo simulation with small sample size equivalent to the magnitude of our study's sample size. One demonstrates sufficient power for a general multidimensional scaling model with the number of clusters up to 4 [75]. Another examines power issues for hierarchical cluster models in the correct identification of the "true" number of partitions and the cluster size and also used simulation study on a small sample size dataset [76].To improve the representativeness of the sample, we recruited diverse participants from across the U.S. Nonetheless, our small sample size limits the generalizability of our findings. Our sample appeared representative with regard to age and gender, though less so with respect to race [77]. Our pilot study findings relied on self-report, which may have led to a tendency for more favorable responses. We did not confirm a diagnosis of chronic pain, but our referral sources made incorrect diagnoses unlikely. The tool is designed to be used online or on a mobile device, thus restricting access for some patients but expanding reach to others. Attempts to obtain provider evaluations of the patient encounter were unproductive. Survey invitations emailed from the study's secure Qualtrics server were frequently blocked from providers' email servers by institutional firewalls, going into spam folders. When firewalls could eventually be bypassed, providers were confused when they received multiple emails about patients they had seen too long ago to remember details of the encounter. Some providers did not understand that they were expected to complete evaluations even if the patient did not share the summary page or was in the control group. Further, we had no contact information for providers of participants referred through patient networks. Addressing firewall barriers prior to study initiation and improving instructions about completing provider surveys may have helped, as would integration into the EHR.

There appears to be an unmet need of patientcentered tools to help manage chronic pain. Decision aids that have been evaluated for chronic musculoskeletal pain are less effective than those developed for other conditions. Furthermore, a public directory of decision aids does not list any available decision aids targeting chronic pain [78]. However, a growing number of mobile pain management Apps are becoming available. A recent review [79] identified 36 mobile pain management Apps, most serving as pain diary tools. However, most of these apps (69\%) did not involve clinicians in App development, none systematically engaged patients with chronic pain in development, and none were considered to be suitable for clinical usage due to lack of HIPAA compliance. That review concluded that there are no pain management Apps designed for clinical use by physicians.

Given the urgency for deploying new approaches to tackle the ongoing opioid epidemic, PainAPP has been embedded into a website (ThePainAPP.com, Additional file 2: Appendix 2) that does not require provider or patient referral, removing the need for prescreening or disclosure of personal identifiers. To avoid the challenges introduces by using a linear, sequential design, patients and providers can choose how they would like to learnbrowsing by topic, using only the Patient Engagement/ Education tool, the Comprehensive Pain Assessment tool, or both.

Misunderstanding patient treatment preferences is widespread and can result in unnecessary or even harmful treatments [80]. Improving the lives of patients with chronic pain requires that patients understand their choices and the consequences of those choices, and that providers understand their patients, which requires good communication between the two. This manuscript illustrates the value of conducting beta-testing of SDM tools in real-world settings before large-scale clinical testing, consistent with other recommendations [51, 81]. This study identifies the treatment goals of patients with chronic pain as well as communication strategies to improve chronic pain discussions from the perspective of both patients and providers. These findings, coupled with lessons learned about designing and testing patientand clinician-centered tools, may provide useful insights for other tool developers. PainAPP appears to be feasible for use at this time, though further adaptation and testing is needed to assess its impact on patients and providers. 


\section{Supplementary information}

Supplementary information accompanies this paper at https://doi.org/10. 1186/s12911-020-01279-8.

Additional file 1: Appendix 1. Exploratory Analyses of Post-provider Visit in each Study Group.

Additional file 2: Appendix 2. Screen Shots from ThePainAPP.com (hosts the PainAPP tool).

\section{Acknowledgements}

None.

\section{Authors' contributions}

Nananda Col made substantial contributions to the conception, design of the tool, design of the study, acquisition of data, analysis of and interpretation of data, creation of the software and drafted the manuscript. $\mathrm{SH}$ made substantial contributions to the conception of the study, the design of the tool, acquisition and interpretation of data and made substantial contributions to the manuscript. VS made substantial contributions to the conception of the study, the design of the tool, interpretation of data, and substantially revised the manuscript. LN made substantial contributions to the conception and design of the study and interpretation of data, and revised the manuscript. EM made substantial contributions to the design of the tool, acquisition and interpretation of data. SG made substantial contributions to the design of the tool and interpretation of data, and substantially revised the manuscript. MS made substantial contributions to the design of the tool and acquisition and interpretation of data. NG made substantial contributions to the conception and design of the study and interpretation of data. NN made substantial contributions to the acquisition and interpretation of data. BT made substantial contributions to the conception and design of the tool and acquisition and interpretation of data. FS made substantial contributions to the design of the tool and acquisition and interpretation of data. RE made substantial contributions to the design of the tool and acquisition and interpretation of data. LP made substantial contributions to the design of the study and the tool, interpretation of data, and substantially revised the manuscript. The authors read and approved the final manuscript

\section{Funding}

Financial support for this study was provided by an independent research grant from Pfizer Independent Grants for Learning \& Change with Five Islands Consulting LLC. The funding agreements ensured the authors' independence in designing the study, interpreting the data, writing, and publishing the report. We have no ongoing financial arrangements with the funder.

\section{Availability of data and materials}

The datasets used and/or analyzed during the current study are available from the corresponding author on reasonable request.

\section{Ethics approval and consent to participate}

This study was approved by the University of New England Independent Review Board for the Protection of Human Subjects in Research (012616019). All subjects gave written informed consent.

\section{Consent for publication}

Form Attached. This manuscript has not been previously published and is not under consideration in any other peer-reviewed media.

\section{Competing interests}

NC has received consulting fees and research contracts from various entities through her contract research organization, Five Islands Consulting, LLC. Her paid and unpaid research and consulting have included developing and/or evaluating shared decision-making tools for multiple sclerosis (MS), aortic stenosis, atrial fibrillation, chronic pain, sleep apnea, and neurocritical care. Paid consulting included advising Miami University (assessing the quality of medical information), Biogen through their MS Quality Steering Committee, Emmi Solutions in developing decision aids, Wolters Kluwer in updating decision aids, Janssen Scientific Affairs, LLC (training, decision aids), 3D Communications (consulting), Epi-Q (consulting), Synchrony Group (consulting), Mallinckrodt's SpecGx LLC (one-time consulting fee and reimbursement of travel), AceRx (one-time consulting fee and reimbursement of travel), Pacific Northwest University (travel expenses and honoraria), EMD-Serono (travel expenses, speaker fees, and research funding), and Edwards Lifesciences (research funding).

She serves as an unpaid mentor for $2 \mathrm{NIH}$ training (K) grants developing decision tools in the areas of sleep apnea and neurocritical care. She received an independent research grant from MSAA (Multiple Sclerosis Association of America), Pfizer (in the area of chronic pain) and a research grant from Biogen (in the area of MS). She has 2 research grants under consideration: the Association of Community Cancer Centers (ACCC) and EMD Serono.

These authors declare that they have no competing interests: LN, VS, BT, NG, RE, EM, FS, SG, SH, NN, LP, MS.

\section{Author details}

${ }^{1}$ University of New England and Shared Decision Making Resources, 1119 Five Islands Road, Georgetown, ME 04548, USA. ${ }^{2}$ Northern Light Mercy Hospital, Portland, ME, USA. ${ }^{3}$ Beth Israel Deaconess Medical Center, Boston, MA, USA. ${ }^{4}$ Southern Maine Chronic Pain Support Group, Saco, ME, USA. ${ }^{5}$ Custom Communications, Portland, ME, USA. ${ }^{6}$ Sprintz Center for Pain and Dependency, The Woodlands, TX, USA. ${ }^{7}$ Penobscot Community Health Care, Bangor, ME, USA. ${ }^{8}$ Mainehealth, Portland, ME, USA. ${ }^{9}$ University of Massachusetts Medical School, Worcester, MA, USA.

Received: 8 June 2019 Accepted: 30 September 2020

Published online: 17 October 2020

\section{References}

1. Care and Education Committee on Advancing Pain Research, IOM. Relieving pain in America: a blueprint for transforming prevention, care, education, and research. Washington, DC: National Academies Press; 2011.

2. Xu JQ, Murphy SL, Kochanek KD, Bastian B, Arias E. Deaths: final data for 2016. Natl Vital Stat Rep. 2018;67(5):1-76.

3. National Vital Statistics System. Mortality multiple cause-of-death public use data file documentation. Hyattsville: US Department of Health and Human Services; National Center for Health Statistics; 2015.

4. Hedegaard $H$, Minino AM, Warner M. Drug overdose deaths in the United States, 1999-2017. NCHS data Bried; 2018. p. 1-8.

5. Gomes T, Tadrous M, Mamdani MM, Paterson JM, Juurlink DN. The burden of opioid-related mortality in the United States. JAMA Netw Open. 2018; 1(2):180217.

6. Catan T, Perez Evan. A Pain-Drug Champion Has Second Thoughts. Wall Street Journal. 2012. https://www.wsj.com/articles/SB100014241278873244 78304578173342657044604.

7. Mezei L, Murinson BB. Assessment of pain education in N American medical schools. J Pain. 2011:12(12):1199-208.

8. Jeffery MM, Butler M, Stark A, Kane RL. Multidisciplinary pain programs for chronic noncancer pain. Rockville: Agency for Healthcare Research and Quality; 2011

9. Frantsve LM, Kerns RD. Patient-provider interactions in the management of chronic pain: current findings within the context of shared medical decision making. Pain Med. 2007:8(1):25-35.

10. United States General Accounting Offi ce (GAO) Report to the Congressional Re-questers. Prescription drugs: OxyContin abuse and. Diversion and efforts to address the problem. GAO-04-110; 2003.

11. Substance Abuse and Mental Health Services Administration, Center for Sub-stance Abuse Treatment. Methadone-associated mortality: report of a National AssessmentSAMHSA Publication No. 04-3904, ; 2004

12. Matthias MS, Krebs EE, Collins LA, Bergman AA, Coffing J, Bair MJ. "I'm not abusing or anything": patient-physician communication about opioid treatment in chronic pain. Patient Educ Couns. 2013;93(2):197-202. https://doi.org/10.1016/j.pec.2013.06.021 Epub 2013 Aug 2.

13. Marbach J, Lennon MC, Link BG, Dohrenwend BP. Losing face: sources of stigma as perceived by chronic facial pain patients. J Behav Med. 1990;13: 583-604.

14. Edwards LC. The pain beliefs questionnaire: an investigation of beliefs in the causes and consequences of pain. Pain. 1992;51(3):267-72.

15. Lillrank $A$. Back pain and the resolution of diagnostic uncertainty in illness narratives. Soc Sci Med. 2003;57:1045-54. 
16. Upshur CC, Bacigalupe G, Luckmann R. "They don't want anything to do with you": patient views of primary care management of chronic pain. Pain Med. 2010;11:1791-8.

17. Dobscha SK, Corson K, Flores JA, Tansill EC, Gerrity MS. Veterans affairs primary care clinicians' attitudes toward chronic pain and correlates of opioid prescribing rates. Pain Med. 2008:9:564-71.

18. Matthias MS, Parpart AL, Nyland KA, Huffman MA, Stubbs DL, Sargent C, et al. The patient-provider relationship in chronic pain care: providers' perspectives. Pain Med. 2010;11:1688-97.

19. Haythronthwaite JA, Fauerbach JA. Assessment of acute pain, pain relief and patient satisfaction. In: Melzack R, Turk DC, editors. Handbook of pain assessment. 2nd ed. New York: The Guilford Press; 2001. p. 417-30.

20. Jamison RN, Ross MJ, Hoopman P, et al. Assessment of postoperative pain management: patient satisfaction and perceived helpfulness. Clin J Pain 1997;12:229-36.

21. Comley AL, DeMeyer E. Assessing patient satisfaction with pain management through a continuous quality of improvement effort. J Pain Symptom Manag. 2001;21:27-40.

22. McCracken LM, Evon D, Darapas ET. Satisfaction with treatment for chronic pain in a specialty service: primary prospective results. Eur J Pain. 2002;6: 387-93

23. Nelson KA. Consumer decision making and image theory: understanding value-laden decisions. J Consum Psychol. 2004;14:28-40.

24. Reyna VF. A theory of medical decision making and health: fuzzy trace theory. Med Decis Mak. 2008;28:850-65.

25. Lockwood S. "Evidence of me" in evidence-based medicine? BMJ. 2004;329: 1033-5.

26. Karel MJ. The assessment of values in medical decision making. J Aging Stud. 2000;14:403-22.

27. Turner JA, Deyo RA, Loeser JD, Von Korff M, Fordyce WE. The importance of placebo effects in pain treatment and research. JAMA. 1994;271(20):1609-14. https:/doi.org/10.1001/jama.1994.03510440069036.

28. Henry SG, Bell RA, Fenton JJ, Kravitz RL. Goals of chronic pain management: do patients and primary care physicians agree and does it matter? Clin J Pain. 2017;33(11):955-61.

29. Jecker NS. The role of intimate others in medical decision making. Gerontol. 1990;30:65-71

30. Hornberger JC, Habraken H, Bloch DA. Minimum data needed on patient preferences for accurate, efficient medical decision making. Med Care. 1995; 33:297-310.

31. Makoul G. Perpetuating passivity: reliance and reciprocal determinism in physician-patient interaction. J Health Commun. 1998;3:233-59.

32. Street RL Jr, Gordon HS, Ward MM, Krupat E, Kravitz RL. Patient participation in medical consultations: why some patients are more involved than others. Med Care. 2005;43:960-9.

33. Edwards A, Elwyn G. Involving patients in decision making and communicating risk: a longitudinal evaluation of doctors' attitudes and confidence during a randomized trial. J Eval Clin Pract. 2004;10(3):431-7.

34. Col NF. Patient Health Communication to Improve Shared Decision Making. Chapter 17. In: Fischhoff B, Brewer NT, Downs JS, editors. U.S. Department of Health and Human Services, Food and Drug Administration, Risk Communication Advisory Committee Communicating risks and benefits: an evidence-based User's guide. http://www.fda.gov/downloads/AboutFDA/ ReportsManualsForms/Reports/UCM268069.pdf. Accessed 10 Sept 2020.

35. Street RL Jr. Information-giving in medical consultations: the influence of patients' communicative styles and personal characteristics. Soc Sci Med. 1991;32(5):541-8.

36. Gordon HS, Street RL Jr, Sharf BF, Souchek J. Racial differences in doctors' information-giving and patients' participation. Cancer. 2006;107:1313-20 PubMed: 16909424.

37. Street RL Jr, Richardson MN, Cox V, Suarez-Almazor ME. (Mis)understanding in patient-health care provider communication about total knee replacement. Arthritis Rheum. 2009;61:100-7.

38. Frosch DL, May SG, Rendle KA, Tietbohl C, Elwyn G. Being labeled 'difficult' among key obstacles to shared decision making. Health Aff (Millwood). 2012;31(5):1030-8

39. Stacey D, Legare F, Lewis K, Barry MJ, Bennett $C L$, Eden KB. Decision aids for people facing health treatment or screening decisions. Cochrane Database Syst Rev. 2017:4:CD001431.
40. Bowen E, Nayfe R, Milburn N, Mayo H, Reid MC, Fraenkel L, et al. Do decision aids benefit patients with chronic musculoskeletal pain? A systematic review. Pain Med. 2019. https://doi.org/10.1093/pm/pnz280 Epub ahead of print] PubMed PMID: 31880805.

41. Bishop FL, Greville-Harris M, Bostock J, et al. Supporting informed choice in acupuncture: effects of a new person-, evidence- and theory-based website for patients with back pain. Acupunct Med. 2019;37(2):98-106.

42. Fraenkel L, Rabidou N, Wittink D, Fried T. Improving informed decisionmaking for patients with knee pain. J Rheumatol. 2007;34(9):1894-8.

43. Patel S, Ngunjiri A, Hee SW, et al. Primum non no- cere: shared informed decision making in low back pain - a pilot cluster randomised trial. BMC Musculoskelet Disord. 2014;15(1):282.

44. Weymann N, Dirmaier J, von Wolff A, Kriston L, Harter M. Effectiveness of a web-based tailored inter- active health communication application for patients with type 2 diabetes or chronic low back pain: randomized controlled trial. J Med Internet Res. 2015;17(3):e53.

45. Durand M-A, Stiel M, Boivin J, Elwyn G. Where is the theory? Evaluating the theoretical frameworks described in decision support technologies. Patient Educ Couns. 2008;71(1):125-35.

46. Delbecq AL, Van de Ven AH, Gustafson DH. Group techniques for program planning: a guide to nominal group and Delphi processes. Middleton: Green Briar Press; 1975.

47. Potter M, Gordon S, Hamer P. The nominal group technique: a useful consensus methodology in physiotherapy research. N Z J Physiother. 2004; 32(3):126-30.

48. Gallagher M, Hares T, Spencer J, Bradshaw C, Webb I. The nominal group technique: a research tool for general practice? Fam Pract. 1993;10(1):76-81.

49. Scott $D$, Deadneck $D$. The nominal group technique applications for training needs. Train Dev. 1982;36(6):26-33.

50. Witteman HO, Dansokho SC, Colquhoun H, Coulter A, Dugas M, Fagerlin A, et al. User-centered design and the development of patient decision aids: protocol for a systematic review. Syst Rev. 2015;4(1):11.

51. Coulter A, Stilwell D, Kryworuchko J, Mullen PD, Ng CJ, van der Weijden T. A systematic development process for patient decision aids. BMC Med Inform Decis Mak. 2013;13 Suppl 2(Suppl 2):S2. https://doi.org/10.1186/1472-694713-S2-S2.

52. Stacey D, Bennett CL, Barry MJ, Col NF, Eden KB, Holmes-Rovner M, et al. Decision aids for people facing health treatment or screening decisions. Cochrane Database Syst Rev. 2011;10:CD001431.

53. Col NF, Solomon AJ, Springmann V, lonete C, Alvarez E, Tierman B, et al. Evaluation of a novel preference assessment tool for patients with multiple sclerosis. Int J MS Care. 2018;20(6):260-7.

54. Col NF, Solomon AJ, Springmann V, Garbin C, lonete C, Pbert L, et al. Whose preferences matter? A patient-centered approach for eliciting treatment goals. Med Decis Mak. 2018;38(1):44-55.

55. Schiffman SS, Reynolds ML, Young FW. Introduction to multidimensional scaling: theory, methods, and applications. New York: Academic; 1981.

56. Fitzgerald LF, Hubert L. Multidimensional scaling: some possibilities for counseling psychology. J Couns Psychol. 1987;34(4):469-80.

57. Kruskal JB, Wish M. Multidimensional scaling. Beverly Hills: Sage Publications; 1978

58. Aldenderfer MS, Blashfield RK. Cluster analysis. Beverly Hills: Sage Publications; 1984

59. de Vries P, Stiggelbout K, Feldman-Stewart D. Theory-informed design of VCM. Soc Sci Med. 2013:77:156-63.

60. Potter RB, Beach LR. Imperfect information in pre-choice screening of options. Org Beh Human Dec Proc. 1994;59(2):313-29.

61. Elwyn G, O'Connor A, Stacey D, et al. Developing a quality criteria framework for patient decision aids: online international Delphi consensus process. BMJ. 2006;333(7565):417.

62. Available at www.youtube.com/embed/PkTzG-Rka24. Accessed 9/11/2020.

63. Washington TA, Fanciullo GJ, Sorensen JA, Baird JC. Quality of chronic pain websites. Pain Med. 2008:9(8):994-1000.

64. CAHPSR Clinician \& Group Survey: Overview of the Questionnaire. Document No. 2350. 2015.

65. Edwards A, Elwyn G, Hood K, et al. The development of COMRADE-a patient-based outcome measure to evaluate the effectiveness of risk communication and treatment decision-making in consultations. Patient Educ Couns. 2003;50:311-22. 
66. Banta-Green CJ, Von Korff M, Sullivan MD, Merrill JO, Doyle SR, Saunders K The prescribed opioids difficulties scale: a patient-centered assessment of problems and concerns. Clin J Pain. 2010;26(6):489-97.

67. Hamann J, Langer B, Winkler V, Busch R, Cohen R, Leucht S, et al. Shared decision making for in-patients with schizophrenia. Acta Psychiatr Scand. 2006;114(4):265-73.

68. Crutzen R, Cyr D, de Vries NK. The role of user control in adherence to and knowledge gained from a website: randomized comparison between a tunneled version and a freedom-of-choice version. J Med Internet Res. 2012; 14(2):e45.

69. Yank V, Laurent D, Plant K, Lorig K. Web-based self-management support training for health professionals: a pilot study. Patient Educ Couns. 2013;9(1): 29-37.

70. Skeff KM, Stratos GA. Georgetite, Bergen MR. evaluation of a medical faculty development program: a comparison of traditional pre/post and retrospective pre/post self-assessment ratings. Eval Health Prof. 1992;15(3): 50-366.

71. Howard GS, Ralph KM, Gulanick NA, Maxwell SE, Nance DW, Gerber SK. Internal invalidity in pretest-posttest self-report evaluations and a reevaluation of retrospective pretests. Appl Psychol Meas. 1979;3(1):1-23.

72. Howard GS, Millhan J, Slaten S, O'Donnell L. Influence of subject responsestyle effects on retrospective measures. Appl Psychol Meas. 1981;5:144-50.

73. Pratt C, McGuigan M, Katzev R. Measuring program outcomes: using retrospective pretest methodology. Am J Eval. 2000;21:341-9.

74. Nimon K, Zigarmi D, Allen JM. Measures of program effectiveness based on retrospective pretest data: Are all created equal? Am J Eval. 2010;32:8-28.

75. Baker FB, Hubert L. Measuring the power of hierarchical cluster analysis. J Am Stat Assoc. 1975;70(349):31-8.

76. Rodgers JL. Matrix and stimulus sample sizes in the weighted MDS model: empirical metric recovery functions. Appl Psych Meas. 1991;15:71-7.

77. Dahlhamer J, Lucas J, Zelaya C, et al. Prevalence of chronic pain and highimpact chronic pain among adults - United States, 2016. MMWR Morb Mortal Wkly Rep. 2018:67:1001-6.

78. A to Z Inventory of Decision Aids. The Ottawa Hospital Research Institute. https://decisionaid.ohri.ca/AZsearch.php?criteria=chronic+pain, Accessed on 11 Sep 2020.

79. Zhao P, Yoo I, Lancey R, et al. Mobile applications for pain management: an app analysis for clinical usage. BMC Med Inform Decis Mak. 2019;19:106. https://doi.org/10.1186/s12911-019-0827-7.

80. Barry M. Stop the silent misdiagnosis: patients' preferences matter. BMJ. 2012;345:e6572.

81. Kistin C, Silverstein M. Pilot studies. A critical but potentially misused component of interventional research. JAMA. 2015;314(15):1561-2.

\section{Publisher's Note}

Springer Nature remains neutral with regard to jurisdictional claims in published maps and institutional affiliations.

Ready to submit your research? Choose BMC and benefit from:

- fast, convenient online submission

- thorough peer review by experienced researchers in your field

- rapid publication on acceptance

- support for research data, including large and complex data types

- gold Open Access which fosters wider collaboration and increased citations

- maximum visibility for your research: over $100 \mathrm{M}$ website views per year

At $\mathrm{BMC}$, research is always in progress.

Learn more biomedcentral.com/submissions 